\title{
Pengaruh Latihan Lompat Kardus Terhadap Hasil Lompatan Jauh Gaya Jongkok Pada Siswa SD Negeri 132 Palembang
}

\author{
Reza Resah Pratama ${ }^{a}$ \\ ${ }^{a}$ Universitas Sriwijaya, Palembang Sumatera Selatan 30151, Indonesia \\ Corresponding author:
}

\section{ART ICLE INFO}

Article history:

Received 07 Februari 2018

Received in revised form 25

Februari 2018

Accepted 25 Maret 2018

Keywords: Cardboard jump,

long jump style squatting,

improved results

\begin{abstract}
A B S T R A C T
This study aims to determine how big the influence of cardboard jump exercise on the long jump style of squatting on students of State Elementary School 132 Pelembang. This type of research is experiment. Where the sample of students of State Elementary School 132 which amounted to 30 male students divided into 2 groups by ordinal pairing, ie 15 people experimental group given the treatment of cardboard jumping exercise and 15 people who were not given treatment. To determine the sample size can be calculated at least $20-25 \%$ of the existing popu- lation. To determine the sample by using random sampling technique and to divide the treatment and control group by ordinal pairing based on the pre test result after the research, it is concluded that there is the effect of cardboard jump exercise on the long jump style of squatting on the students of Elementary School 132 Palembang. In this cardboard jump exercise is a leaping motion that uses one leg and lands on two legs with the aim of obtaining a leap that far away. Data collection techniques used initial and final test techniques. The statistics used to analyze the data in the study using $t$ test. The result of $t$ test shows that ttable test $=1.70$ whereas tcount $=3,49, \mathrm{dk}=28$ and $=5 \%$, so. Thus reject Ho and accept Ha which states there is the effect of cardboard jump exercise on the long jump style of squatting on students of Elementary School 132 Palembang.
\end{abstract}

\section{Pendahuluan}

\subsection{Latar Belakang}

Pendidikan jasmani yang berpangkalan dari gerak manusia serta mengarah pada kepribadian yang bulat dan kreatif dari manusia. Pendidikan jasmani merupakan media untuk mendorong perkembangan motorik, kemampuan fisik, pengetahuan dan penalaran, Penghayatan nilai-nilai sikap, mental, emosional, spritual dan sosial serta pembiasaan pola hidup sehat yang bermuara untuk merangsang pertumbuhan dan perkembangan yang seimbang. Pendidikan jasmani memiliki peran yang sangat penting dalam mengintensifkan penyelenggaraan pendidikan sebagai suatu proses pembinaan manusia yang berlangsung seumur hidup. Pendidikan jasmani memberikan kesempatan pada siswa dan siswi untuk terlibat langsung dalam aneka pengalaman belajar melalui aktivitas jasmani, bermain dan berolahraga yang dilakukan secara sistematis, terarah dan terencana. Pembekalan pengalaman belajar itu diarahkan untuk membina, sekaligus membentuk gaya hidup sehat dan aktif sepanjang hayat.

Dalam proses pembelajaran di sekolah sangatlah penting pendidikan jasmani. Melalui pendidikan jasmani diharapkan siswa dapat memperoleh berbagai pengalaman untuk mengungkapkan kesan pribadi yang menyenangkan, kreatif, inovatif, terampil, meningkatkan dan memeliharan kesegaran jasmani serta pemahaman terhadap gerak anak itu sendiri. Tujuan utama pendidikan jasmani di sekolah dengan memberikan materi-materi yang merangsang anak untuk bergerak dan sudah di atur dalam setandar kompetensi (SK) dan 
Kompetensi Dasar (KD).

Berdasarkan (Kosasi, 1994:2),

Pendidikan jasmani (Physical Education) adalah suatu bagian dari keseluruhan pendidikan yang mengutamakan aktivitas jasmani dan pembinaan hidup sehat untuk pertumbuhan dan pengembangan jasmani, mental, sosial, dan emosional yang serasi, selaras, dan seimbang. Pengembangan jasmani juga bertujuan untuk pembinaan olahraga prestasi yang dapat dicapai apabila ditunjang oleh berbagai pengembangan disiplin ilmu yang erat kaitannya dengan olahraga itu sendiri. Untuk mencapai prestasi yang tinggi dalam bidang olahraga kesegaran jasmani yang tinggi para olahragawan adalah persyaratan yang tak dapat diabaikan, di samping koordinasi, keseimbang, kecepatan, kelincahan dan daya ledak.

Untuk itu kesegaran jasmani harus ditingkatkan kemampuannya. Prestasi olahraga tidak dapat diciptakan dalam waktu yang singkat tetapi memerlukan waktu proses pembinaan yang lama. Untuk memperoleh prestasi yang optimal diperlukan suatu latihan yang kontinu dan terprogram. Dengan kata lain untuk mencapai prestasi olahraga perlu latihan sedini mungkin.

Latihan lompat-lompat adalah latihan yang mempersiapkan otot tungkai untuk bekerja secara efektif dan efisien, disamping itu latihan tersebut juga ditujukan untuk mengembangkan kekuatan dan kecepatan karena adanya peningkatan sistem dan fungsi organ tubuh serta peningkatan efisiensi kerja sehingga menghasilkan daya ledak yang dapat meningkatkan prestasi atlet. Banyak cabang olahraga yang membutuhkan lompatan khususnya lompat jauh dalam atletik. Lompat jauh adalah olahraga yang membutuhkan daya ledak otot tungkai. Daya ledak otot tungkai disini dapat ditingkatkan dengan cara latihan beban, seperti : squat jump, skips, hops, leaps dan lompat kardus. Oleh karena itu banyak latihan beban yang dianggap dapat meningkatkan daya ledak otot tungkai. Maka peneliti tertarik untuk meneliti salah satu bentuk latihan tersebut yaitu lompat kardus, karena pembebanan pada saat melakukan lompat kardus terletak pada otot tungkai.
Cabang Olahraga Atletik yang meliputi gerakan jalan, lari, lempar dan lompat adalah cabang olahraga yang paling tua di dunia. Hal ini karena umur olahraga atletik sama tuanya degan adanya manusia-manusia yang pertama di dunia. Aktivitas jalan, lari, lempar dan lompat merupakan bentuk-bentuk keterampilan gerak dasar paling asli dan paling wajar dari manusia, serta merupakan gerakan-gerakan yang amat penting salah satu dari nomor dalam cabang atletik adalah lompat jauh yang harus di kuasai seorang pelompat jauh agar perestasi maksimal dapat tercapai.

Berdasarkan hasil observasi yang dilakukan di SD Negeri 132 Palembang didapatkan bahwa hasil lompat jauh gaya jongkok yang dilakukan oleh siswa yang mengikuti kegiatan pembelajaran atletik masih tergolong rendah. Untuk cabang olahraga atletik khususnya lompat jauh di daerah-daerah sulit berkembang karena kurangnya pembinaan dan minat siswa serta tidak adanya seorang pelatih yang berkualitas dalam cabang olahraga atletik pada nomor lompat jauh di bandingkan cabang olahraga sepak bola, bola basket, bola voli. Dari observasi melalui guru penjasorkes hasil lompat jauh siswa SD Negeri 132 Palembang belum memuaskan, rata-rata hanya mencapai $30 \%$ dari yang ditetapkan. Dalam kaitanya dengan uraian di atas, maka penulis tertarik untuk melakukan penelitian yang berjudul "Pengaruh Latihan Lompat Kardus Terhadap Hasil Lompat Jauh Gaya Jongkok Pada Siswa Sd Negeri 132 Palembang".

\subsection{Rumusan Masalah}

Berdasarkan uraian di atas, maka masalah yang akan diteliti dapat dirumuskan Apakah ada Pengaruh Latihan Lompat Kardus Terhadap Hasil Lompat Jauh Gaya Jongkok Pada Siswa SD NEGERI 132 Palembang.

\subsection{Tujuan Penelitian}

Tujuan dari penelitian ini adalah untuk mengetahui Pengaruh Latihan Lompat Kardus Terhadap Hasil Lompat Jauh Gaya Jongkok Pada Siswa SD NEGERI 132 Palembang. 


\subsection{Landasan Teori}

\subsubsection{Pengertian Atletik}

Istilah atletik berasal dari kata dalam bahasa Yunani yaitu "atlhlon" yang berarti berlomba atau bertanding (Tamat, 2005:2.3). Cabang olahraga atletik terdiri dari empat nomor perlombaan yang masing-masing adalah nomor lari, lempar, lompat dan jalan cepat, oleh karena itu atletik disebut juga dengan istilah track and field. Track artinya lintasan, nomor-nomor lintasan seperti lari dan jalan cepat, field artinya lapangan, nomor-nomor lapangan seperti lempar dan lompat. (Muhajir, 2006:35).

\subsubsection{Lompat jauh}

Lompat jauh merupakan salah satu nomor dalam cabang atletik yang menurut Kosasi (1994 :24), "lompat adalah melakukan suatu bentuk gerakan lompatan dengan tujuan untuk memperoleh hasil lompatan sejauh-jauhnya atau setinggi tingginya dengan menggunakan tolakan satu kaki”. Menurut Roji ( 2006 :66 ) "gerakan lompat jauh dapat dibagi atas: awalan, tumpuan atau tolakan, melayang serta mendarat di bak pasir. Gerakan-gerakan tersebut dikenal dengan istilah teknik dasar lompat jauh. Gaya dalam lompat jauh menurut Muhajir (2006: 40) terbagi tiga, yaitu gaya jongkok, gaya lenting atau gaya gantung dan gaya berjalan di udara”.

\subsubsection{Latihan Lompat Kardus}

Lompat kardus adalah suatu kegiatan yang dilakukan oleh siswa dalam menumbuhkan keberanian untuk melakukan lompatan melewati halangan / rintangan berupa kardus bekas tempat air minum mineral yang diletakkan di depan siswa untuk dilompati. (Suharto 2012:10).

Adapun kelebihan latihan dengan alat meningkatkan power otot tungkai. Siswa menjadi lebih termotivasi karena adanya kompetensi kardus. Gerakannya menyerupai gerakan menumpu pada lompat jauh gaya jongkok. Sedangkan kelemahan dari latihan dengan alat bantu kardus adalah beban tubuh diangkat lebih berat karena melompat dengan satu kaki dan mendarat dengan menggunakan dua kaki.

\subsubsection{Kerangka berfikir}

Sebelum diberi perlakuan seluruh subjek penelitian atau sampel penelitian diadakan pretes lompat jauh. Setelah itu baru diberikan perlakuan atau latihan berupa latihan lompat kardus. Terakhir setelah perlakuan diberikan diadakan postest untuk melihat pengaruh yang terjadi terhadap hasil lompat jauh gaya jongkok.

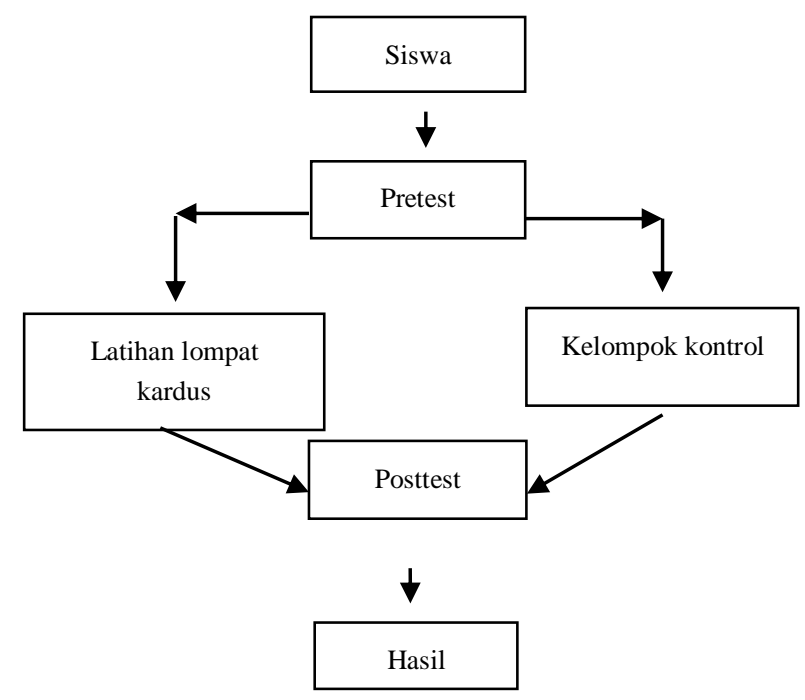

Gambar 2.3 : Skema kerangka berpikir

\subsubsection{Hipotesis penelitan}

Berdasarkan kajian di atas ,maka hipotesis yang diajukan peneliti adalah ada pengaruh latihan lompat kardus terhadap hasil lompat jauh gaya jongkok pada siswa SD negeri 132 Palembang.

\section{Metode Penelitian}

\subsection{Jenis dan Rancangan Penelitian \\ 2.1.1 Jenis Penelitian}

Jenis penelitian yang digunakan dalam penelitian ini adalah "Metode eksperimen merupakan penelitian yang dimaksud untuk mengetahui ada tidaknya akibat-akibat dari "sesuatu" yang digunakan pada subjek" (Arikunto, 2010 :160). Metode eksperimen adalah metode yang digunakan untuk mencari pengaruh perlakuan tertentu terhadap yang lain dalam kondisi yang terkendalikan, dengan kata 
lain penelitian eksperimen adalah meneliti ada tidaknya pengaruh sebab akibat. Dalam penelitian ini, peneliti menggunakan metode penelitian eksperimen atau action research. (Sugiyono,2010:107)

Penelitian eksperimen atau action research dilakukan dengan maksud untuk mengetahui pengaruh latihan lompat kardus terhadap hasil lompat jauh gaya jongkok siswa SD Negeri 132 Palembang.

\subsubsection{Rancangan Penelitian}

Penelitian ini termasuk penelitian eksperimen, dikarenakan penelitian ini bertujuan untuk mengetahui sejauh mana pengaruh latihan lompat kardus sebagai variabel bebas (X) terhadap hasil lompat jauh gaya jongkok sebagai variabel terikat $(\mathrm{Y})$.

\subsection{Variabel Penelitian}

Sebagai variabel bebas dalam penelitian ini adalah latihan lompat kardus. Sedangkan variabel terikat dalam penelitian ini adalah hasil lompat jauh gaya jongkok.

\subsection{Populasi dan Sampel}

\subsubsection{Populasi}

Populasi pada penelitian ini adalah siswa SD Negeri 132 Palembang dengan jumlah seluruh populasi 116.

\subsubsection{Sampel Penelitian}

Sampel dalam penelitian yang diambil sebanyak $25 \%$ dari jumlah populasi 116 orang yaitu 29 dibulatkan menjadi 30 orang siswa.

\subsection{Teknik dan Alat Pengumpulan Data}

Langkah pertama yang dilakukan oleh peneliti adalah mengumpulkan sampel untuk dilakukan tes awal (pretest), setelah mendapatkan hasil barulah dibagi menjadi dua kelompok secara random sampling kemudian diurutkan dengan cara oridinal pairing kelompok pertama kelompok yang diberi perlakuan latihan lompat kardus selama 4-6 minggu, kelompok kedua tidak di beri perlakuan. Setelah latihan selama 4-6 minggu barulah seluruh sampel diberikan tes akhir (posttest) untuk mengetahui kelompok mana yang lebih meningkat.

\subsection{Teknik Analisis Data}

\subsubsection{Uji Normalitas Data}

$$
k=\frac{\bar{x}-m_{0}}{s}
$$

Keterangan :

$\mathrm{K}=$ Kemiringan.

$\bar{x}=$ Rata-rata .

$\mathrm{M}_{0}=$ Modus.

$\mathrm{S}=$ Simpangan.

Data dikatakan normal jika nilai $\mathrm{K}$ terletak antara -1 sampai +1 $(-1<\mathrm{Km}<+1)($ Sudjana, $2005: 109)$.

\subsubsection{Uji Homogenitas}

$$
X^{2}=(\ln 10)\left\{B-\sum\left(n_{1}-1\right) \log s_{1}^{2}\right\}
$$

Sampel itu akan homogen jika $X^{2}$ hitung $\leq X^{2}$ table, dan sampel tidak homogen jika $X^{2}$ hitung $\geq$ dari $X^{2}$ table (Sudjana, $2005: 263$ ).

\subsection{Uji Hipotesis}

Bila data yang diperoleh berdistribusi normal dan homogen, maka digunakan statistik Uji t, dengan

$$
\text { rumus: } \mathrm{t}=\frac{M x-M y}{\sqrt{\left(\frac{\sum x^{2}+\sum y^{2}}{N_{x}+N_{y}-2}\right)\left(\frac{1}{N_{x}}+\frac{1}{N_{y}}\right)}}
$$

(Arikunto, 2010:311)

Keterangan :

$\mathrm{M}=$ Mean dari perbedaan pretest dan posttest

perkelompok

$\mathrm{n}=$ banyak mean

$\mathrm{x}=$ deviasi setiap nilai $\mathrm{x}_{2}$ dan $\mathrm{x}_{1}$

$\mathrm{y}=$ deviasi setap nilai $\mathrm{y}_{2}$ dan $\mathrm{y}_{1}$

$\mathrm{x}=$ kelompok eksperimen

$\mathrm{y}=$ kelompok kontrol

Dalam penelitian ini penulis mengambil taraf signifikan 5\%, Kriteria pengujian adalah terima Ho jika $\mathrm{t}>\mathrm{t}_{1-\alpha}$ dan tolak Ho jika $\mathrm{t}$ mempunyai harga-harga lain. Derajat kebebasan untuk daftar distribusit ialah $\left(\mathrm{n}_{1}+\mathrm{n}_{2}-2\right)$ dengan peluang $(1-\alpha)$. 


\section{Hasil dan Diskusi}

Hasil pretest kelompok eksperimen diketahui bahwa siswa SD Negeri 132 Palembang hasil lompatan terjauh $265 \mathrm{~cm}$ dan yang terdekat $165 \mathrm{~cm}$ serta rata-rata pretest kelompok eksperimen 218,4 cm. setelah diberi perlakuan latihan lompat kardus selama 6 minggu dengan frekuensi $3 x$ dalam seminggu dengan intensitas $60-85 \%$ dan beban badan sendiri ternyata terdapat kenaikan rata-rata posttest kelompok eksperimen menjadi $224,8 \mathrm{~cm}$. Pada kelompok kontrol yang terjauh $255 \mathrm{~cm}$ dan terdekat $155 \mathrm{~cm}$ dengan rata-rata pretest kelompok control yaitu 209,8 cm.

Latihan yang dipakai untuk meningkatkan lompatan adalah dengan lompt kardus. Penelitian ini telah dilakukan pada siswa SD Negeri 132 Palembang berjumlah 30 siswa. Seluruh sampel melakukan pretest, kemudian hasilnya dirangking dari hasil yang tertinggi sampai yang terendah. Sampel dibagi menjadi 2 kelompok menggunakan sistem ordinal pairing, berdasarkan hasil rangking pretest yaitu 15 orang sebagai kelompok eksperimen dan 15 lagi sebagai kelompok kontrol. Kelompok kontrol tidak diberi perlakuan sedangkan kelompok eksperimen diberi perlakuan berupa latihan lompat kardus selama 6 minggu dengan frekuensi latihan 3 kali seminggu. Setelah 6 minggu di beri latihan, di lakukan tes akhir (posttest).

Setelah data pretest dan posttest di dapat, dilakukan uji normalitas dan homogenitas sebagai syarat analisis data. Setelah di uji ternyata data pretest dan postest berdistribusi normal dan homogen. Selanjutnya dapat dilakukan pengajuan hipotesis menggunakan statistik "uji t". Kriteria pengujian hipotesis terima Ho Jika

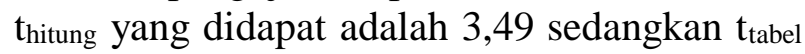
adalah $\mathrm{t}$ yang diperoleh dari tabel distribusi $\mathrm{t}$ dengan $\mathrm{dk}=28$ dan taraf kepercayaan 95\% ( $\alpha$ $=0,05)$. Untuk $t_{\text {tabel }}(95 \%)$ diperoleh harga 1,70 sehingga $t_{\text {hitung }}$ dengan taraf signifikan 0,05 lebih besar dibandingkan $t_{\text {tabel }}$ yaitu 3,49 $>$ 1,70. Dengan demikian tolak $H o$ dan terima $\mathrm{Ha}$ yang menyatakan bahwa ada pengaruh latihan lompat kardus terhadap hasil lompat jauh gaya jongkok pada siswa SD Negeri 132 Pelembang.

\section{Simpulan dan Saran}

\subsection{Kesimpulan}

Berdasarkan hasil penelitian dan analisis data yang menggunakan tekhnik statistik uji t,dapat di tarik kesimpulan sebagai berikut:

1. Dari analisis data terdapat perbedaan antara rata-rat pre test dan posttest pada klompok eksperimen yaitu $\mathrm{X}$ pre $=218,4$ $\mathrm{X}$ pos $=224,8$ dan analisis data kelompok kontrol $\mathrm{X}$ pre $=209,8 \mathrm{X}$ pos $=$ 208,8 beda antara kelompok eksperimen dan kelompok kontrol yaitu nilai beda $\left(\mathrm{X}_{\text {eksperime }}=6,4\right.$ dan $\left.\mathrm{Y}_{\text {kontrol }}=-1\right)$. Melalui pengujian hipotesis dengan menggunakan uji $\mathrm{t}$ di dapatkan harga sebesar $t_{\text {hitung }}=3,49$ sedangkan harga $\mathrm{t}_{\text {tabel }}=1,70$

2. Berdasarkan hasil analisis data uji t maka Ho ditolak sehingga ada pengaruh latihan lompat kardus terhadap hasil lompat jauh gaya jongkok pada siswa SD Negeri 132 Palembang.

\subsection{Saran}

Berdasarkan kesimpulan di atas, maka penulis memberi saran-saran sebagai berikut:

1. Bagi guru pendidikan jasmani olahraga dan kesehatan agar dapat memilih metode latihan yang tepat untuk anak didik, dan dapat memberikan motivasi dalam latihan dan belajar dalam berolahraga sehingga timbul minat siswa dalam meningkatkan prestasi olahraga.

2. Bagi peserta didik berlatilah dengan tekun yang sesuai dengan bakat dan kemampuan yang anda miliki untuk mencapai prestasi yang diinginkan.

Bagi sekolah agar dapat memfasilitasi dan memberikan sarana dan prasarana kepada siswanya untuk melakukan aktifitas olahraga 


\section{Daftar Pustaka}

Deni dan suro.(2010). Pendidikan jasmani dan kesehatan, Jakarta. Cv thursina

Harsono.(1988). Caoching dan AspekAspek Psikologis dalam Coaching, Jakarta:Depdikbud.

Khomsin.(2011). Atletik 1, Semarang. UNESS

Kosasih, Engkos.(1995). Pendidikan jasmani dan kesehatan, Jakarta: erlangga

Muhajir.(2006). Pendidikan jasmani olahraga dan kesehatan, Bandung. Erlangga

Roji.(2006). Pendidikan jasmani olahraga dan kesehatan, sidoarjo. Erlangga

Sudjana.(2005). Metoda Statistika, Bandung: Tarsito.

Suharsimi, arikunto.(2006). Metode Penelitian, Jakarta: P.T. Bumi Aksara

Sugiyono.(2010). Metode Penelitian Pendidikan, Bandung: Alfabeta

Suharto.(2012). Penerapan pembelajaran modifikasi lompat kardus untuk meningkatkan hasil belajar lompat jauh sisswa kelas VIII smp negeri 39 Surabaya. Universitas negeri surabaya 